\title{
The Distinctiveness of Polyamory
}

\author{
Luke Brunning \\ luke.brunning@philosophy.ox.ac.uk
}

\begin{abstract}
Desires for intimacy that bypass the couple or the life narrative it generates have no alternative plots, let alone few laws and stable spaces of culture in which to clarify and cultivate them. What happens to the energy of attachment when it has no designated place? To the glances, gestures, encounters, collaborations, or fantasies that have no canon? ${ }^{1}$
\end{abstract}

\section{Introduction}

Much has changed since Lauren Berlant wrote those words in 1998. Non-monogamous and uncoupled people are increasingly visible and are shaping theoretical discussion of relationships, sexuality, and love. ${ }^{2}$ As more people openly build their lives with multiple partners, it becomes difficult to agree with Robert Nozick, who opined that, "it is not feasible for a person simultaneously to be part of multiple romantic couples (or a trio), even were the person to desire this" ${ }^{3}$ or with Robert Solomon, who claimed, "if one can love more than one person romantically, it will certainly be a source of conflict." 4

I shall defend the viability of polyamory. Polyamory is a form of consensual non-monogamy that Nozick and Solomon would deem unfeasible. To render it palatable to critics, activists and theorists often accentuate polyamory's similarity to monogamy. I argue that this strategy conceals the distinctive character of polyamorous intimacy. A more discriminating account of polyamory helps me answer objections to the lifestyle whilst heeding its unique pitfalls.

In section two, I define polyamory, and explain why people become polyamorous. Many think polyamorous intimacy is inferior and I describe four main objections in section three. In section four, I explain how commitment to "the polyamorous possibility" prompts one to viscerally experience personal, practical, and social constraints. Unlike monogamous dynamics, these confrontations are mediated by third parties who destabilize the familiar dynamics of coupled life. Polyamory can be emotionally challenging but, as I outline in section five, it is sustained by interpersonal emotional work that helps people understand their emotions, communicate without confrontation, and contain the difficult emotions of others. This work is qualitatively and quantitatively intensified in polyamory. In sections six and seven, I address the objections to polyamory whilst acknowledging some of its distinct pitfalls.

\section{Polyamory}

Monogamous norms historically concerned marriage. They prohibited marriage to multiple people at once, and regulated sequential marriages. ${ }^{5}$ Today, however, monogamy describes the confinement of one's romantic and sexual attention to one person at a time. (Monogamous relationships are dyadic and exclusive). ${ }^{6}$ 
People deviate from monogamy in various ways; from adultery, to swinging, or polyamory. Unlike cheating, polyamory is a paradigmatic form of consensual non-monogamy. ${ }^{7}$ Alexis Shotwell defines polyamory as "the practice of consensually and with mutual interest negotiating desire for more than one relationship". ${ }^{8}$ This definition, which perhaps surprisingly says nothing of love, aptly captures the complexity of polyamory. ${ }^{9}$ It reflects the fact that one can be polyamorous without currently being in a relationship; it is silent on the subjects of the desire in question (one partner in a couple may desire multiple relationships, the other not); and it captures the honest and interpersonal character of polyamory.

Deborah Anapol suggests that, "the form [a polyamorous] relationship takes is less important than the underlying values”. ${ }^{10}$ Unlike Shotwell, however, she emphasizes the centrality of love:

the freedom of surrendering to love and allowing love-not just sexual passion, not just social norms and religious strictures, not just emotional reactions and unconscious conditioningto determine the shape of our intimate relationships is the essence of polyamory. ${ }^{11}$

Neither definition foregrounds sex, which is fitting because the connection between sexual desire and polyamory is not straightforward. Someone with limited sexual desire, for instance, may pursue a polyamorous relationship so their partner can be fulfilled sexually. Polyamory is notable for privileging emotional intimacy with others. Such intimacy is typically guarded against in other forms of consensual non-monogamy. ${ }^{12}$

All forms of polyamory are characterized what Christian Klesse calls "the basic axiom": honesty.$^{13}$ Polyamorous people aim to be honest about their feelings, desires, and expectations. This honesty helps polyamorists explicitly shape their relationship boundaries, which take different forms. Some polyamorous relationships have a defined hierarchical structure, often involving "primary partners" who might live together, share finances, or raise children. ${ }^{14}$ Such partners are privileged in terms of time, emotional involvement, and decision making. ${ }^{15}$ Other polyamorists eschew explicit hierarchy on principle or because there is no natural 'core' couple. This often happens in "vee” relationships, where Beatrice simultaneously has a relationship with Adam, and a relationship with Claire, but Adam and Claire are not in a relationship with each other. ${ }^{16}$

Polyamory has broad appeal because it resonates with two diverging political outlooks. Some find polyamory accords with individualistic liberalism because it values autonomy and explicit choice. As one of Elizabeth Sheff's interviewees puts it:

polyamory helps me, especially as a woman, to keep my autonomy so I don't lose myself...It helps me to define what I want and set my boundaries and take relationships at what [sic] I need. ${ }^{17}$

Other people are drawn to a communitarian vision of polyamory. They want to nurture wider intimate groups without limiting romantic intimacy to the traditional couple.

Either way, polyamory can appear to remedy the perceived failures of monogamy. Most people have seen relationships falter for lack of individual autonomy, or through want of variety. In 
pursuing a relationship that prizes honesty, communication, and the possibility of further intimacy, perhaps one can avoid a faltering relationship from the offset.

For some, polyamory offers a way to accommodate the burgeoning intimacy they are already experiencing, such as love for someone other than their partner. In those situations, polyamory offers an honest and considerate way of nurturing affection for multiple people.

However, the impact of having multiple relationships is not simply additive. It is qualitatively different. Robert Solomon captures an important dimension of romantic love when he argues love "is the mutual creation of self-identity." 18 He argues that whilst one's sense of self emerges in concert with many others, particularly one's caregivers and friends, romantic love makes a "definitive" difference. Romantic love, with its attendant vulnerability, draws another person beyond the many fragments of one's public self, to a perspective of greater intimacy, where one is seen as a stable unity. ${ }^{19}$

Solomon thinks that "one and only one other person" may play this stabilizing role. ${ }^{20}$ Polyamorous people will disagree. Whilst love might help to forge the self, one's fragmented parts can be unified from different perspectives. Thus some pursue polyamory because they value the experience of being seen as "a different person", in the eyes of multiple people. This experience can be playful, revelatory, and pleasurable; it also helps diminish love's idealizations, because it is harder to endorse a single inflated conception of oneself.

The effort people invest in romantic life, searching for 'the one', attests to many people's strong desire for companionship, intimacy, and love; and the pleasure people take in the activities of seduction, conversation, flirtation, dating, seems largely non-instrumental. But these aspects of human sociality are stifled by mononormativity: the ideal that love, intimacy, and sex ought only be offered to one person. ${ }^{21}$ Many polyamorous people place fewer limits on these activities. They value the process of exploring human intimacy rather than the goal of securing a partner. ${ }^{22}$

Put differently, many polyamorous people are unwilling to endorse what Nathan Rambukkana calls the "hegemonic fantasises" of mononormative society. These include "the perpetuation of arbitrary categorical distinctions between sexual and non-sexual forms of intimacy”, such as friendship and more 'significant' relationships, and "the assumption that only certain forms of intimacy [e.g. love, and sex] can be articulated together to constitute coherent or desirable life structures." ${ }^{23}$ Polyamory suits people whose attractions disrupt the binary of the intimate and nonintimate.

Polyamory is also conducive to self-development. For instance, it can help people explore their sexuality. Polyamorous bisexuals can have relationships with differently gendered partners, and multiple relationships can enable one to explore BDSM even if one's partner is uninterested. Polyamory is often a route to a life of abundance, variety, and pleasure.

Other polyamorous people value the emotional challenges of the lifestyle. Polyamory may help someone address aspects of their character they perceive to be negative, such as their selfishness or jealousy, or change their general approach to relationships. The religiously minded, from Fundamentalist Mormons to Buddhists, describe this value in spiritual terms. ${ }^{24}$ Others, enticed by 
polyamory's utopian possibilities think these instrumental benefits can support new forms of social life.

Finally, polyamory can reflect social change. As financial and geographical pressures alter family life, many embrace families of choice. ${ }^{25}$ Polyamorous networks can help people cope with the instability of modern living.

\section{Strategic Similarities}

Much writing about polyamorous relationships stresses their similarity to monogamous relationships. One of Meg-John Barker's interviewees is typical: “I don’t think [polyamory is] vastly different to monogamous relationships. Romantic relationships are always about the same kinds of things: fun, friendship, sex." 26 This rhetorical strategy is motivated by theoretical, political, and ethical concerns.

Theoretically, romantic love is usually characterised as having an exclusive and dyadic focus. But if one heeds how polyamorous people describe their emotional experiences, and there is no prima facie reason not to, this characterisation appears false, and polyamorous love looks similar to monogamous love. ${ }^{27}$

Politically, polyamorist activists seeking legal rights are incentivized to highlight the similarities between polyamory and monogamy. They challenge lawmakers on the grounds of consistency: polyamorous relationships sufficiently resemble monogamous ones, because they honour values of love and commitment, therefore they should have comparable legal protections. ${ }^{28}$

People stress polyamory's similarity to monogamy to rebuff ethical criticism. ${ }^{29}$ Whilst some criticism is hasty and defensive other objections are better formulated. Here are four objections.

First, one might think polyamory leads inexorably to the objectification or commodification of other people, because one uses them to sate one's sexual or emotional greed. Angie Young, for instance, in her review of The Ethical Slut, an influential guide to consensual non-monogamy, asks:

isn't it curious how polyamorous relationships replicate the disposable throw away values of our capitalistic society, treating other people as objects to satisfy our cravings, interchangeable as we please, useful to us only as long as they work for our own purposes? ${ }^{30}$

This criticism resembles Bonnie Zare's analysis of the ideology of adultery in America:

in our sale-bound, mall-oriented culture, variety and novelty are often automatically construed as inherently good... "shopping" for new partners matches well with American society's ruling ideology of consumerism-its obsessive focus on new products. ${ }^{31}$ 
Secondly, polyamory is purportedly immature because it impedes proper attachment to one's partners. For instance, Robert Masters thinks, "multi-partner relating generally bypasses (and is a distraction from) deep attachment" ${ }^{32}$ because:

if we have more than one lover, then when things get rocky with one, we can just go to another, instead of staying with and working in depth with that rockiness and its underpinnings; thus can we keep ourselves removed from getting as attached as we might if we were to be with only one deep intimate. ${ }^{33}$

Masters also thinks that non-monogamous relationships have "fuzzy" boundaries that eroticize "unresolved issues (like the fear of abandonment or craving being wanted or craving being in control." 34 This worry, resting on assumptions about the nature of attachment, eroticism, and polyamorous motivations, resonates with a common understanding of intimacy throughout the lifecycle with individuals purportedly progressing from exploratory to mature relationships.

Thirdly, one may object that polyamory stretches people 'too thinly'. A similar objection was often raised against polygamy. Expressed generally, the thought is that relationships flourish only if one has the resources, practical and emotional, to sustain them; that individuals have limited resources; and thus that polyamory demands more resources than an individual could provide. Consequently, at least some constituent relationships in polyamorous life will not flourish.

A fourth objection is that polyamory is risky, precarious, and akin to a piecemeal life. John Cottingham critiques someone who lives this way. They may:

\footnotetext{
manage to live quite well, for weeks or months or even years...But his life, I suggest, will be less stable. He gets along all right by accident, as it were....although the way he lives has not so far been such as to threaten his happiness and security (or those of others), there are, in the very nature of the case, various tensions in his way of living that are always waiting to surface, and which, in moments of crisis, may erupt to damaging effect. ${ }^{35}$
}

Many think polyamory is inherently unstable because it must generate jealously and other difficult emotions. Whilst some may avoid jealousy "by accident", it is unreasonably risky to pursue polyamory, just as Cottingham thinks it is unreasonable to have a piecemeal life.

These four objections portray polyamory as infeasible or inferior. ${ }^{36}$ Whilst there are similarities between polyamory and monogamy, the desire to defuse these objections should not obscure the important differences, such as the challenges generated by polyamorous life and the emotional practices that sustain the lifestyle. (Matters that are orthogonal to the contingent social dominance of monogamy.) I must first outline these two distinct features of polyamory in order to provide a convincing response to the above objections.

\section{Confronting the "Polyamorous Possibility"}

Polyamorous people often describe how transformative it is to realise that monogamy is optional. As Elizabeth Sheff puts it, "once it has occurred to someone that openly conducted, multiple- 
partner relationships are possible and can be managed in an ethical manner, they can never unthink that idea." 37

Polyamory is provocative. Most people jump to the view that it is obviously unworkable, surely wrong, and that their partner would disapprove. These reactions seem motivated by anxiety because awareness of polyamory can make people consider the status of their relationships.

Anxious reactions are usually brief. But if one commits to the "polyamorous possibility", Sheff's term for "the mind-set that acknowledges the potential to love multiple people at the same time," ${ }^{38}$ then one is provoked in a sustained and multifaceted way. The difference I have in mind is analogous to that between a cursory engagement with feminist ideas and substantive consciousness raising: the latter has a lasting impact on one's behaviour.

Commitment to polyamory involves the stable intention to explore the prospect of nurturing nonmonogamous intimacy in one's life. This exploration includes introspection, imagination, conversation with likeminded people, and emotional processing. Such commitment need not involve actively seeking to form new relationships. One can be polyamorous without currently having a relationship just as one does not need a partner to be monogamous or question one's sexuality.

Sustained engagement with polyamory prompts one to explore one's desires. As Shotwell made clear, polyamorous people must negotiate the desire for multiple relationships. But this rather abstract desire usually follows on the heels of others, such as a desire to nurture intimacy with a specific person, or for different kinds of sex, or to lead a more fulfilling life, and so on. In general, knowing what one wants, and avoiding idealisation, is not straightforward. This process is exacerbated by monogamous ideals which make it challenging to describe and communicate desires for alternative forms of intimacy. ${ }^{39}$

Exploring polyamory can reveal tensions between one's desires and needs or capacities. For example, one's desire to foster intimacy with multiple partners can be frustrated by one's lack of time, need for childcare, or one's prohibitive social anxiety. It is easy to overestimate one's readiness to accommodate new partners or commit to experiencing uncertain emotions.

The task of confronting one's desires, and managing the personal aspects of polyamory, intersects unavoidably with the task of confronting broader social facts. One cannot loosen commitment to monogamous ideals without grappling with how pervasive they are, and without scrutinising the basic components of relationships. These considerations are deeply linked: to think about honesty is to think about communication, and to think about communication is to think about power, and so on.

In exploring polyamory, people retreat from what Mark Finn calls "relationships as maximum security institutions" that have an implicit conception of trust as "relying on the avoidance of attractive alternatives...to produce relational security through a series of exclusions and, importantly, the policing of these". ${ }^{40}$ To foster intimacy beyond an existing relationship one must rethink what trust and commitment involve. Commitment may seem less a process of defending 
an initial contract, and more an ongoing process of affirming one's desire to forge a relationship with another person.

Norms of communication are enmeshed with norms of commitment, trust, and honesty. If one thinks commitment is an ongoing process, one must develop a communicative practice so it can be affirmed; if one thinks honesty is central to intimate life, one must have the communicative resources to foster openness. Honesty is easily frustrated in an angry or defensive environment, and commitment can wane if one is uncommunicative.

In turn, when one grapples with new communicative practices whilst exploring polyamory one must contest received imbalances of power. One's attempt to articulate challenging feelings, or newly experienced desires, can be hindered by implicit power dynamics within a relationship, and by intersecting social norms that structure gender, race, and sexuality. Much practical writing about polyamory aims to help people recognize and address these dynamics. ${ }^{41}$

It's one thing to wrangle with polyamory's uncertain normative landscape but another to explore it directly. When one's commitment to the polyamorous possibility leads to meeting people and new relationships one must grapple with the practical aspects of the lifestyle. Suddenly, one is faced with questions about how to spend time with other people, how to afford it, how to balance relationships with work or childcare, how to maintain one's sexual health, and so on. The practical impact of polyamory is extensive and potentially unsettling.

These practical matters typically intensify the process of contesting mononormative ideals of commitment, trust, and power. One might be happy, in principle, for one's partner to date other people, but there is nothing quite like having to find the money or time to make it possible to expose residual tensions and implicit conceptions of appropriate behaviour. Latent sexism and entitlement can creep into the cracks generated by practical considerations.

Committing to the polyamorous possibility is difficult. Even if alternative intimacies were socially acceptable, the experience of navigating relationships with multiple people remains personally revelatory. One's desires may clash, or jostle against everyday constraints and the needs of other people. Slowly, one learns about oneself in facing these potentially frustrating realities.

In actuality, because most societies are hostile to polyamory, these encounters are especially uncertain, dramatic, and resonant. The private attempt to shape an intimate life is shadowed by the visceral experience of social norms whose full force is only felt as one prepares to violate them. Because one cannot rely on one's social inheritance, on received conceptions of relationships, the heady realisation that intimate life can be redesigned is accompanied by the awareness that definitive blueprints for doing so are unavailable.

Moreover, these confrontations are mediated by other people. The commitment to exploring polyamory is a commitment to the visceral reality of others, particularly to one's romantic partners. Franklin Veaux and Eve Rickert, for instance, fittingly preface their guide to polyamory with Iris Murdoch's resilient maxim, "love is the extremely difficult realisation that something other than oneself is real." ${ }^{42}$ Murdoch's preceding sentence is "love is the perception of 
individuals.” Polyamory fosters these realisations and moments of loving perception. Whilst attempts to nurture intimacy with multiple people are not automatically free of love's distortions, its excesses of fantasy or insecurity, it is harder to overlook the reality of another person when, together, you must negotiate the boundaries of your continuing affection. Polyamorous relationships are less likely to glide along rails of routine, presupposition, and denial.

One could object forcefully that these confrontations are common to all kinds of relationship as long as they are sufficiently intimate and the individuals involved are sufficiently thoughtful. Even the most tacitly bound of monogamous couplings involve the negotiation of some boundaries. ${ }^{43}$ Have I overstated the distinctiveness of committing to polyamorous possibility? In short: no.

Polyamory generates confrontations that distinguish it from monogamous intimacy. All relationships must manage the actual or threatened presence of other people. Adam Phillips suggests that, "the couple is a resistance to the intrusion of the third, but in order for it to last it is indispensable for it to have enemies. That is why the monogamous can't live without them." ${ }^{44}$ Couples define their identity, in part, through a series of implicit exclusions that distinguishes their intimacy from other kinds of relationship or person. Romance is demarcated from friendship, and the particular relationship is contrasted dramatically with ex-relationships. These implicit exclusions are embedded in the rituals, routines, and idiolects of monogamous life and replace the need to actively define a relationship.

Polyamorous relationships are different because they involve sustained and intimate confrontations with third parties. For most polyamorous people this party is another person, e.g. someone one's partner wishes to date. For people who explore polyamory without having a current relationship this third 'party' is an imagined perspective that cannot be ignored when considering the possibility of being open to multiple relationships e.g. the fact that one's next partner could be dating other people.

The active presence of third parties destabilises the internalised dynamics of monogamous life. One must think again. The expansive idiolects of coupledom are thrown into relief and people must work afresh to forge shared narratives. This is especially the case regarding the future because the prospect of a third party drags one off the steady "relationship escalator", with its markers of deepening commitment and intimacy as dating segues into exclusivity, cohabitation, marriage, and children.

This destabilising experience resembles the discovery of an affair, the arrival of a child, or a couple's foray into joint counselling. It is visceral. Unlike the opaque presence of imagined exlovers in the lives of monogamous couples, but like the analogous adulterer, child, or councillor, the third parties in most polyamorous lives are people who become stakeholders in one's future. However, unlike a monogamous person's contingent relationship to adultery, childbirth, and therapy, the presence of a third party is a constitutive feature of polyamory.

Even if one is able to intimate what polyamory entails, practical commitment to the lifestyle is surprising, as Sheff explains in reference to her own experience: 
many people anticipate their multi-partner relationships working out differently in their imaginations than the actual relationships do in real life. In my case, this translated into my virtual certainty that I would be uncomfortable and jealous if Rick [her partner] had other partners, and his virtual certainty that he would not experience jealousy of me and my imagined girlfriend. What happened surprised us both: I was not at all jealous of Rick's tryst with Joya, and Rick was quite jealous of my interactions with Steve. ${ }^{45}$

All relationships are unpredictable but Anapol is right to say that polyamory is "inherently more complex" than monogamy, at least in practical terms. ${ }^{46}$ (And more complex than other forms of consensual non-monogamy, like swinging, that exclude emotional intimacy.) As this complexity increases, so does the potential for further destabilisation; the addition of new partners to one's intimate network always risks further unsettling confrontations. Hence why polyamorous people think their attitude to relationships constitutes a lifestyle: it is a continuing process of clear and open engagement with others.

Explorations of polyamory are emotionally charged. They expose one to anxiety and uncertainty. As in any relationship, fear and anxiety can motivate defensive or manipulative behaviour. This behaviour can harm one's partner. It can also obscure one's relationship to one's own mind because defensive anxiety, and the desire to avoid negative emotions, muddles one's ability to understand oneself. Whilst these are real risks of committing to polyamory, the lifestyle also leaves people in a good position to address them in virtue of its second distinctive feature: its unique emotional work.

\section{The Emotional Work of Polyamory}

All relationships require people to process their emotions in concert with their partners. The nature of these processes are shaped by social ideals. In mononormative society, "needing to talk", for example, is a feared remedial measure rather than a sign of emotional health. As attested by many romantic comedies, these norms are especially powerful at the beginning of relationships when romantic ideals trump communicative clarity.

To sustain a relationship one must engage in what Cheshire Calhoun, following Arlie Hochschild, calls "emotional work". Emotional work is the activity of engaging with another person's emotional life. It involves, "the management of others emotions - soothing tempers, boosting confidence, fueling pride, preventing frictions, and mending ego wounds." ${ }^{47}$ For Calhoun, this interpersonal dimension of ordinary life is "a familiar moral activity that nevertheless escapes moral recollection and reflection." ${ }^{48}$ It is a form of "moral mediation" 49 that aids people to manage their agency by helping them to interpret their mental life. ${ }^{50}$

Calhoun thinks that emotional work is central to everyday life. Noticing this fact, she suggests, should inform an ethical outlook that is not dyadic, or agent centred, but "deeply cooperative". ${ }^{51}$ Emotion work is pervasive, has prima facie ethical importance, and has a central place in any ethics of care. ${ }^{52}$

Emotional work is a crucial constituent of polyamorous relationships. Polyamory generates a range of challenging emotions. Jealousy is an example, but merely one; other positively 
experienced emotional states can be just as challenging. What polyamorists call "new relationship energy" is a prime example: the excitement, lust, and attention that accompanies a new relationship can be consuming. ${ }^{53}$

As I interpret the notion, polyamorous emotion work has several core features. Taken together they can be regarded as an ideal capacity. First, one is best able to relate to one's partners if one can engage with them in a non-confrontational manner. This involves the ability to convey one's state of mind in clear assertive language. For example, Adam's statement to Beatrice: "I feel jealous when you are on a date with Claire" does not blame Beatrice. Non-confrontational engagement also involves the ability to listen to others without interrupting or being swayed by defensiveness. Beatrice, in hearing Adam's statement, might have to restrain her desire to defend her date with Claire, or to refer to an occasion where Adam prompted her to feel jealous.

Non-confrontational communication fosters relationships in which people can fully feel their emotions, rather than defensively trying to avoid feeling them, or feeling them under duress. This is especially pertinent in polyamorous life because third parties may feel under pressure to avoid feeling emotions such as insecurity or deepening intimacy that threaten an established relationship.

One is better able to parse one's emotional experiences if one can feel and communicate one's state of mind. This interpretative facet of emotional work is usually interpersonal. The experience of apparent jealousy is a good example of an experience that can need interpretation. Anxiety, insecurity, fear, and other negative associations and memories are often mistaken for jealousy, and legitimate jealousy can be accompanied by other negative emotions. Moreover, jealousy is prompted for a range of characteristic reasons that can be easily confused with each other. ${ }^{54}$ For example, Beatrice could engage with Adam to help him dissect his negative emotional experience. Together they may consider whether Adam is jealous of Claire in some respect, or whether he feels low self-esteem and insecurity; perhaps he is afraid that Beatrice's attraction to Claire threatens his relationship with her.

Grappling with mental life, whether one's own or that of another, is rarely easy. Relationships generate intense emotions, and even if one is not the object of an emotion, such as a partner's anxiety, it can be unpleasant to have it levelled in one's direction. Therefore, another facet of emotional work is the ability to contain someone's difficult emotions. Containment is a psychoanalytic concept. It describes the psychoanalyst's task of withstanding, processing, and returning, an analysand's transferences, i.e. emotional experiences shaped by past events and unconscious associations. ${ }^{55}$ This task is important because it enables the analysand to emote without recrimination, and also because it establishes the analyst as a trustworthy interlocutor who can tolerate a troubled mind. ${ }^{56}$ Containment abounds in ordinary life, not just in psychoanalyst's consulting room (there it is merely intensified). Polyamorous people need to contain the emotional consequences of their often complex interactions, such as a partner's insecurity or their new relationship energy. If they can withstand these emotions, instead of being hostile or defensive, they can support their partner's emotional understanding and establish themselves as a cooperative, mediating, presence. 
Finally, emotional work involves maintaining useful practices of emotional management. Polyamorous people typically make time to "check in" with their partners, even if there is nothing obvious to talk about, because the practice of regular communication can itself prompt people to explore awkward feelings, thus preventing them from blooming into anxiety or resentment. These practices might follow heuristics, such as the rule that it is unwise to have important discussions whilst a partner is experiencing acute jealousy. ${ }^{57}$ The routines of emotion management support the other features of emotional work.

Again, one might object that emotion work is central to all intimate relationships. There are several reasons, however, to think that polyamory's emotional work is qualitatively and quantitatively intensified. First, even if one just drifts into a polyamorous relationship (a rare occurrence), or is naturally emotionally articulate, one's openness to, or engagement in, relationships with multiple people demands emotional work if only for their sake. Polyamory requires one to intimately engage with the emotional lives of more people than if one was monogamous, especially if one’s partners themselves have multiple partners.

Secondly, because polyamory is practically complex there will be more occasions where explicit emotional work is needed. The impact of more relationships in one's life is multiplicative not additive. This remains the case even if one's relationships flourish, because regular check-ins, and self-directed emotional work, are a core feature of most polyamorous relationships.

Thirdly, polyamory exposes people to unfamiliar, even unique, emotions. Paradigm examples are emotions that take the romantic partner of one's partner as their object. Revelations of infidelity aside, emotions with this character are absent in monogamous relationships. Therefore, these emotional experiences are typically challenging to undergo, describe, and communicate. There are no solid cultural scripts to help one relate to the romantic partners of one's romantic partner. Moreover, unlike exposed infidelity, these emotions are often positive. For example, many polyamorous people describe their experiences of "compersion", which Sheff defines as "the joy at seeing one's partner(s) happily in love with others." ${ }^{8}$ Compersion is a complicated and understudied emotional experience. Is it the obverse of jealousy, an instance of empathy, or something distinct? Irrespective of how best to analyze the emotion, compersion appears unique to certain forms of consensual non-monogamy. This partly explains why some people think these lifestyles can be transformative, because one can have powerful and novel emotional experiences.

Fourthly, note that all relationships are evaluated in comparison to examples of other relationships in one's social context, like those of family and friends, and to one's past relationships. These relationships inform one's personal standard of what constitutes nurturing or abusive behavior. Polyamory differs from monogamy because one's comparative thinking is also influenced by one's multiple concurrent relationships. Thus one's evaluations are laced with realism and less likely to be distorted by hindsight or fantasy.

Finally, one's ability to relate well to other people improves with practice. Early relationships are fraught with misunderstandings and mistakes. Polyamorous people are no different but their learning is accelerated. There is nothing quite like negotiating multiple relationships at the same time, over time, to improve one's ability to navigate any relationship and to learn from one's mistakes. 
My account of emotional work describes several capacities that tend to be exercised in polyamorous life. Individuals will vary in the extent to which their emotional work approximates the ideal I have described, and some will be better than others. As with the exercise of any capacity, people improve with practice. Polyamorous relationships tend to provide people with this practice largely irrespective of whether they want it or not. One cannot maintain polyamory whilst evading the emotional needs of other people.

Polyamorous relationships are practically complex and often emotionally charged. Even if one is atypically resilient, insensitive, or unemotional, it is unlikely that all of one's partners will be too (or in the same respects). Thus one's relationships are likely to falter if one does not engage with their emotional lives.

Furthermore, consider Anapol's description of the necessary conditions underpinning polyamory:

Polyamory can take many forms, but as it was originally conceived, if deception or coercion is involved or if the people involved are out of integrity in any way, it is not polyamory no matter how many people are sexually involved with each other. ${ }^{59}$

On this understanding, emotional work is arguably a constitutive feature of polyamory because it manifests one's commitment to honesty and integrity. If one is unwilling to engage with the emotional lives of one's partners, one is not truly polyamorous.

I am not presupposing that the fruits of emotional work are quick to ripen, or that everyone experiences them to the same extent. Much depends on one's underlying ability to relate well to other people. However, even if one struggles, the process of engaging in emotional work with one's partners makes polyamory possible, and predisposes one to secure a range of benefits.

Prolonged mediation in concert with one's partners, that is aimed at forging a diverse intimate life, refines one's understanding of how to relate well to other people. One learns how to avoid being manipulative or domineering; one can avoid conflicts that arise when the desires or needs of other people are neglected; and one learns how to address tensions without being confrontational.

As these capacities develop, one is better able to nurture the kind of intimacy that made polyamory seem attractive to begin with, to forge an abundant life, to be shaped by multiple people, and to address stifling aspects of one's character, such as a propensity to insecurity or anxiety. This is not to deny that emotional work is challenging, occasionally onerous, but this typically subsides over time as people develop strategies of emotion management.

\section{Reconsidering Polyamory}

Polyamorous relationships prompt distinct confrontations with oneself and others, mediated by third parties. These relationships are sustained by emotional work. The character of these confrontations, and this work, distinguishes polyamorous intimacy from the monogamous norm. Noting these differences allows me to offer better replies to those who object to polyamory. 
The first objection to polyamory was that it involves a toxic combination of commodification, objectification, and greed. This objection betrays an impoverished understanding of why people pursue polyamory. It portrays people as implicitly seeking to secure various 'goods' in their relationships, rather than wanting to nurture intimacy and love for other people, to honour the values fostered in any relationship, or to try and become an emotionally receptive person. Furthermore, greed is defined relative to a social conception of what is appropriate. Therefore, to object that polyamory manifests greed is to risk presupposing mononormative ideals of 'the one' relationship, ideals that polyamorous people contest. Moreover, the emotional work underpinning polyamory helps one nurture the intimate life of other people, which seems contrary to greed. Finally, all relationships can involve the objectification or commodification of another person. Even if one presupposes these attitudes are always morally questionable (which is not selfevident), the emotional work internal to polyamory, coupled with the fact that one is scrutinised by multiple partners, puts one in a good position to identify and address these attitudes.

The second objection to polyamory was that it is immature or precludes secure attachment to other people. Attachment theory studies how people have a "biological proclivity to form attachments". ${ }^{60}$ The attachment bond has three significant features: the maintenance of proximity, the attachment figures as a secure base, and as a safe haven. ${ }^{61}$ Infants desire closeness to an attachment figure, typically a parent; to return to the figure when threatened; and are disposed to use the attachment figure as a base around which to explore their world. These behaviours persist throughout the lifecycle.

There is some evidence to think that one's adult relationships are shaped by the attachment style one develops in infancy. To take just one example, a study of a group of women discovered that "women who strongly endorsed both the avoidant and ambivalent attachment styles were more likely to have difficulties in their love relationships and friendships than women who endorsed a single attachment style." ${ }^{62}$

I must stress two points, however. First, these studies suggest there are connections between attachment styles and later relationship dynamics, which inverts the causal links central to the objection that polyamory leads to impeded attachment. Secondly, whilst there appear to be studies linking attachment style and the dynamics of later relationships, I know of no established link between attachment style and relationship form. The links between attachment and polyamory are unclear and little studied.

That said, anecdotal evidence suggests that polyamory is not only compatible with, but actively fosters, secure attachment. The emotional work internal to polyamory helps defuse anxiety and insecurity, and can short-circuit more manipulative forms of defensive behavior. Furthermore, many polyamorous people have core relationships. These units can provide a secure base that enables each partner to confidently explore other relationships without fear of jeopardizing their intimacy. One can speculate whether a greater number of "secure bases" are better than fewer? This reflects common intuitions about parenting (and friendship) i.e. that having multiple figures of attachment is good, and one could draw an analogous conclusion regarding polyamory in suggesting that people with multiple intimate relationships increase, not diminish, their potential for secure attachment. At the very least, Anapol is right to think that, "neither monogamy or 
polyamory has a corner on immaturity, and people can gravitate towards both from a position of maturity or its opposite." 63

The third objection to polyamory was that one will inevitably lack sufficient resources to nurture good relationships. This criticism bears the imprint of the version historically leveled at polygyny (plural marriage between men and multiple women); namely, that one man cannot provide sufficient resources for multiple wives and children. Most polyamorous people reject the presuppositions underpinning this objection such as the patriarchal idea that women should be dependent on men and that significant romantic relationships should aim at raising children.

More positively, many polyamorous people emphasize the ways their relationships expand their resources. Sheff, for example, documents the ways in which polyamorous families have more resources when raising children: more adults in the family mean there is potentially more money, time, and social support available. ${ }^{64}$ Polyamorous groups without children may also find their lifestyle provides them with greater emotional support, as there are more people to talk to, learn from, and interact with daily; that is, a greater number of life experiences and perspectives bear on any one individual's situation.

The fourth objection to polyamory was that it is precarious, particularly because it exposes people to jealousy and other negative emotions. All relationships involve risks and offer rewards, so much hinges on one's understanding of risk. With respect to negative emotions like jealousy, one can distinguish between the risk such emotions will arise, and the risk they will be damaging when they do arise.

There is evidence to doubt whether jealousy is more likely to arise in polyamorous relationships. ${ }^{65}$ Even if one presupposes that jealousy and other negative emotions like anxiety are more likely, it remains an open question whether these emotions are more likely to have a destructive impact on the relationship. The emotional work internal to polyamory helps partners to understand, communicate, and work through negative emotions together. Unlike many monogamous relationships, the boundaries and emotional norms of polyamory are explicitly defined by the parties involved, partly to accommodate the possibility of negative emotions. Thus polyamorous people are well placed to confront negative emotions and prevent them from leading to manipulative or defensive behavior.

Still, monogamous relationships may look more stable than polyamorous relationships because one only has to accommodate the desires and practical life of one person. However, I want to distinguish between two ways an intimate life could be stable: from the inside, and from the outside. If one's intimate life is internally stable, it has fewer points of potential friction; fewer divergent interests, desires, and temptations. This is the stability of specialization. In contrast, if one's life is externally stable, it is likely to be more abundant and varied. One might have several relationships with different people, and those relationships might focus on divergent activities, projects, or desires. This is the stability of diversification. When people suggest polyamorous relationships are unstable, and "certainly.... a source of conflict", as Solomon put it, they typically have internal stability in mind. They overlook the fact that polyamorous relationships are usually more externally stable. Polyamory is more resistant to external shocks, such as illness, breakups, changes in income, and the general mutability inherent in all relationships; both in terms of its 
form, because one has multiple partners for support, and in terms of its content, as emotional work helps one confront change. If this stability can be coupled with sufficient internal stability, and I think it can, then polyamorous lives appear more stable.

\section{Polyamorous Pitfalls}

The common objections to polyamory fail because they rest on inadequate understandings of what polyamory involves and why it is attractive. One would be mistaken, however, to think polyamory lacks its own risks. These potential problems arise in virtue of the fact that one is negotiating the desire for intimacy with multiple people. As such they are unique to, or typically arise within, polyamorous relationships; a fact that is easily obscured by the rhetorical emphasis on the similarities between polyamorous and monogamous relationships.

Mononormative societies are structured around a teleological ideology of 'the one': the individual who eventually completes one's life by being the singular source of romantic love, sexual affection, and emotional intimacy. Polyamorous people find this ideal personally stifling, and socially insidious in its characterization of romantic love. Yet in rejecting 'the one', and committing to the polyamorous possibility, polyamorous people risk erecting an ideal of 'the many' in its place.

The ideal of 'the many' upholds, as a polyamorous norm, a conception of an intimate life with multiple partners who interact harmoniously, share interests, projects, and goals, and communicate without difficulty. Like the ideal of 'the one', this conception is unrealistic and damaging. It has no place for partners who prefer to maintain a respectful separation from each other, or who are radically different, and it underpins criticism of people who do not feel compersion towards their partner's partners. The ideal of the many might resonate with people who are drawn to the utopian possibilities of new forms of intimate life, but it risks overlooking the various practical constraints, and emotional challenges, that comprise daily life as a polyamorous person.

As I stressed in section five, emotional work lies at the heart of polyamorous practice, and is much discussed in various guides to the lifestyle. By and large the emphasis on clear non-confrontation communication, and the nuances of interpersonal mediation, is positive. But if misappropriated it can be problematic.

First, the complexity of polyamorous relating can lead people to fixate on relationships at the expense of the people within them. Relationships are reified, regarded as interesting topics of conversation and analysis, whilst the concrete needs of one's partners are neglected or marginalized. Such fixation can arise in monogamous relationships, but it is arguably more likely in polyamorous life with its explicit focus on the active articulation of relationship boundaries, ongoing emotional work, and clear communication.

Secondly, the polyamorous emphasis on communication can be exaggerated. This can be inhibiting, as talking replaces action, and analysis replaces uninhibited emotion. More problematically, this attitude can marginalize people who are less articulate. It risks portraying polyamory as an exclusive and highly cognitive form of intimate life. This portrayal is at odds 
with most people's understandings of what is integral to polyamory: being led by one's affection for other people with honesty and integrity.

Similarly, the emphasis on communication can easily foster the policing of relationships and their boundaries, typically by a dominant or more articulate partner. Whilst the articulation and negotiation of boundaries is a core aspect of polyamory, people must also be able to express uncertainty about them and the emotions they generate, and have space to reconsider how best to lead an intimate life. The policing of boundaries and the enforcement of communicative norms can subtly pressure people into inauthentic attempts to be clear and determinate about uncertain aspects of their life.

Finally, emotional work is often interpersonal and requires people to contain their partners' challenging emotions. Containment helps people undergo, describe, and communicate their emotional experiences. Some partners, however, can be disproportionality burdened by this containing role. This often arises if people engage in "triangular communication", that is, if they talk to one partner about an issue arising from their relationship with another partner. ${ }^{66}$ Triangular communication not only impedes direct communication with the relevant party, something that can be manipulative, but it burdens the intermediary who has to bear and process emotions for which they are not responsible or implicated.

No doubt polyamory has other associated risks and problems. But it is important to note that the potential issues described above are nearly all excesses of one kind or another; instances of too much of a good thing, namely, emotional work and the clear articulation of relationship boundaries. These deficits are analogous to over-sensitivity rather than the absence of sensitivity.

Moreover, whilst polyamory is clearly not immune from difficulties, polyamorous people are well positioned to remedy these problems as a consequence of their emotional work with their partners. The practical challenge of living a polyamorous life increases the likelihood that one will develop and deepen the emotional and communicative capacities that help one identify and address problems. Even if one struggles personally in developing these traits, in living polyamorously one also increases the chance one will benefit from the skills and abilities of others as they help one negotiate this complex form of intimate life.

\section{Conclusion}

Polyamorous relationships have a distinct character. Their complexity prompts challenging confrontations of one's desires, emotions, practical context, and social world. These confrontations are shaped by third parties. They destabilize the traditional dynamics of coupled life. Grappling with polyamorous intimacy is exciting and scary, but polyamory is sustainable when people learn to engage with their emotions. This emotional work is interpersonal and fosters good relationships with other people.

Critics of polyamory overlook what it involves and why people pursue the lifestyle. This selective focus makes polyamory seem inferior to monogamy or unfeasible. It is neither. Polyamory has its own pitfalls, but many of those arise as a byproduct of people striving to enact ideals of honesty 
and clear communication. Moreover, over time polyamorous people become well placed to identify and remedy their mistakes in concert with their partners.

I have not argued that polyamorous relationships, in virtue of their form, promise better kinds of intimacy that monogamous relationships. But it is clear, in light of what I have argued and in light of how polyamorous people describe their motivations and everyday life, that such an argument can be made. Polyamory appears to be an ethical form of life. At the very least, it is high time philosophers sympathetic to Nozick and Solomon replaced assertion with argument to show why polyamorous people are mistaken. ${ }^{67}$

\footnotetext{
${ }^{1}$ Lauren Berlant, 'Intimacy: A special issue.' Critical Inquiry, 24, 2 (1998) p.285

${ }^{2}$ For an overview see Meg-John Barker \& Darren Langdridge, 'Whatever happened to non-monogamies? Critical reflections on recent research and theory', Sexualities, 13, 6 (2010) pp.748-77, and the introduction to Nathan Rambukkana, Fraught Intimacies: Non/monogamy in the Public Sphere (UBC Press, 2015)

${ }^{3}$ Robert Nozick, 'Love’s Bond.' In The Examined Life: Philosophical Meditations (Simon \& Schuster, 1989) p.84

${ }^{4}$ Robert Solomon, About Love: Reinventing romance for our times (Indianapolis; Hackett Pub, 2006) p.39

${ }^{5}$ Historically, what we call "serial monogamy” was called "successive polygamy". See John Witte Jr, The Western Case for Monogamy over Polygamy (Cambridge University Press, 2015) p.31

${ }^{6}$ cf. Carrie Jenkins, 'Modal Monogamy', Ergo, 2,8 (2015) pp.175-94 Relationships can be exclusive but non-dyadic, e.g. a triad, or a dyadic but non-exclusive, e.g. a couple with a “don't ask, don't tell” agreement. ${ }^{7}$ Another term used is "ethical non-monogamy", which I avoid because I'm examining the ethical status of polyamory.

${ }^{8}$ Alexis Shotwell, 'Ethical Polyamory, Responsibility, and Significant Otherness.' Forthcoming. Italics in the original.

${ }^{9}$ I sidestep whether polyamory is an "orientation”. cf. Christian Klesse, 'Polyamory: Intimate practice, identity or sexual orientation?’ Sexualities, 17, 1 (2014) pp.81-99.

${ }^{10}$ Deborah Anapol, Polyamory in the 21st century: Love and intimacy with multiple partners. (Rowman \& Littlefield Publishers, 2010) p.5

${ }^{11}$ Ibid.

${ }^{12} \mathrm{cf}$. Meg-John Barker, 'This is my partner, and this is my...partner's partner: Constructing a polyamorous identity in a monogamous world.' Journal of Constructivist Psychology, 18, 1 (2005), pp.75-88; Barker \& Langdridge op. cit. p.750; Christian Klesse, 'Polyamory and its 'others': Contesting the terms of nonmonogamy.' Sexualities, 9, 5 (2006), pp.565-583; and Elizabeth Sheff, The Polyamorists Next Door. (Rowman \& Littlefield, 2014) pp.1-22

${ }^{13}$ Klesse op. cit. p.571

${ }^{14}$ Sheff op. cit. pp.17-20

${ }^{15}$ cf. Franklin Veaux \& Eve Rickert, More Than Two: A practical guide to ethical polyamory (Thorntree Press, 2104) chapters 9-12.

${ }^{16}$ Veaux \& Rickert op. cit. p.458

${ }^{17}$ Sheff op. cit. p.19

${ }^{18}$ Solomon op. cit. p.203

${ }^{19}$ Solomon op. cit. chapter 4

${ }^{20}$ Solomon op. cit. p.207

${ }^{21}$ Meg-John Barker \& Ani Ritchie, 'There aren't words for what we do or how we feel so we have to make them up': Constructing polyamorous languages in a culture of compulsory monogamy. Sexualities, 9, 5 (2006), p.587

${ }^{22}$ cf. Veaux \& Rickert op. cit. p.10
} 
${ }^{23}$ Rambukkana op. cit. p.13

${ }^{24}$ On the instrumental value of Mormon plural marriage, see Peter Marneffe, 'Liberty and Polygamy' in Elizabeth Brake, (ed.) After Marriage: Rethinking Marital Relationships (Oxford University Press, 2105) p.147; for discussion of Buddhism and polyamory, see Brad Warner, Sex, Sin, and Zen: Buddhist Exploration of Sex from Celibacy to Polyamory and Everything in Between (New World Library, 2010).

${ }^{25}$ Cf. Kath Weston, Families we choose: Lesbians, gays, kinship (Columbia University Press, 2013)

${ }^{26}$ Barker 2005 op. cit. p.82

${ }^{27}$ cf. Jenkins op. cit. for an argument to think romantic love need not be dyadic and Troy Jollimore's ambivalent take on the same issue. Troy Jollimore, Love's Vision. (Princeton University Press, 2011) pp.161-67

${ }^{28}$ cf. Elizabeth Brake, Minimizing Marriage (Oxford University Press, 2012) chapter 6. This approach can mask intersectional complexity (Melita J. Noël, 'Progressive polyamory: Considering issues of diversity.' Sexualities, 9, 5 (2006) pp.602-620).

${ }^{29}$ Veaux and Rickert's recent book devotes a chapter to polyamory and ethics (op. cit. chapter 3), which suggests these concerns remain pertinent.

${ }^{30}$ Angi Young, 2004. 'Review of The Ethical Slut: A Guide to Infinite Sexual Possibilities, by Dossie Easton and Catherine A. Liszt.' Off Our Backs (2014) pp.38-9, cited in Rambukkana op. cit. p.195

${ }^{31}$ Bonnie Zare, 'Sentimentalized Adultery': The film Industry's Next Step in Consumerism?' Journal of Popular Culture 35, 3 (2001) p.33 italics added.

32 Robert Masters, Transformation through Intimacy, Revised Edition: The Journey Toward Awakened Monogamy (North Atlantic Books, 2012) p.25

${ }^{33}$ op. cit. p. 24

${ }^{34}$ op. cit. p. 25

${ }^{35}$ John Cottingham, 'Integrity and Fragmentation.' Journal of Applied Philosophy. 27, 1 (2010) p.5

${ }^{36}$ The third and fourth objections are related to the concern that polyamory harms children. I cannot consider this objection here but see Sheff (op. cit. chapters 5-9) and Anapol (op. cit. chapter 7) for detailed discussion.

${ }^{37}$ op. cit. pp.20-21

${ }^{38}$ op. cit. Ibid.

${ }^{39}$ cf. Barker \& Ritchie op. cit.

${ }^{40}$ Mark D. Finn, 'The psychological architecture of the stable couple relationship.' Theory \& Psychology, 22, 5 (2012) p.614

${ }^{41} \mathrm{cf}$. Veaux \& Rickert op. cit. chapters 6 and 7.

${ }^{42}$ Iris Murdoch, 'The sublime and the good.' Chicago Review, 13, 3 (1959), p.51

${ }^{43}$ Katherine Frank \& John DeLamater, 'Deconstructing monogamy: Boundaries, identities, and fluidities across relationships.' in Meg-John Baker and Darren Langdridge (eds.) Understanding non-monogamies (Routledge, 2010) pp.9-22.

${ }^{44}$ Cited in Lisa Appignanesi, All About Love (Norton, 2011) p.213

${ }^{45}$ Sheff op. cit. p.115

${ }^{46}$ Anapol op. cit. p.65

${ }^{47}$ Cheshire Calhoun, Moral Aims (Oxford University Press, 2015) p. 215

${ }^{48}$ op. cit. ibid.

${ }^{49}$ op. cit. p.216

${ }^{50}$ Calhoun notes that emotional work is a "work women do and are expected to do" (p.215), and it is no accident that polyamory, which explicitly requires this work of everyone, is often associated with resistance to gender-norms (cf. Sheff, op. cit. pp.28-30).

${ }^{51}$ op. cit. p. 217

${ }^{52}$ cf. Virginia Held, 'Taking Care: Care as Practice and Value'. In Cheshire Calhoun (ed.) Setting the moral compass: Essays by women philosophers (Oxford University Press, 2003)

${ }^{53}$ Veaux \& Rickert op. cit. p.455

${ }^{54}$ Anapol op. cit. chapter 6 
55 The psychoanalyst Wilfred Bion introduced the term "containment”, (see Wilfred Bion, 'Attacks on Linking', in Elizabeth Spillus \& Edna O'Shaughnessy (eds.) Projective Identification: The Fate of a Concept (Routledge, 2012 [1959])

${ }^{56}$ Robert Caper, A Mind of One's Own (Routledge, 1999) p.14

${ }^{57}$ Anapol op. cit. p.124

${ }^{58}$ op. cit. p.20 cf. Barker \& Ritchie op. cit. p.595

59 op. cit. p.5 italics added.

${ }^{60}$ Peter Fonagy, Attachment Theory and Psychoanalysis (Karnac Books, 2001) p.7 cf. John Bowlby, Attachment (Pimlico, 1997); John Bowlby, A Secure Base (Routledge, 2005)

${ }^{61}$ Cindy Hazan \& Phillip Shaver, 'Attachment as an Organizational Framework for Research on Close Relationships', Psychological Inquiry, 5, 1 (1994) p.4

${ }^{62}$ Gerard McCarthy, 'Attachment style and adult love relationships and friendships: A study of a group of women at risk of experiencing relationship difficulties', British Journal of Medical Psychology, 74 (1999) p.315

${ }^{63}$ op. cit. p.38

${ }^{64}$ Sheff op. cit. p.196. A range of intersecting factors, such as race, class, and wealth, mean that various social groups may be disproportionality privileged by their polyamorous lifestyle. cf. Rambukkana op. cit. p.159

${ }^{65}$ Terri Conley, et. al. 'A critical examination of popular assumptions about the benefits and outcomes of monogamous relationships.' Personality and Social Psychology Review 17, 2 (2013)

${ }^{66}$ Veaux \& Rickert op. cit. p.99

${ }^{67}$ I am grateful for the support of Meg-John Barker, Matthew Broome, Carrie Jenkins, Patricia Marino, Laurencia Saenez, Kate Tomas, Sheila Udeagu, two anonymous referees for this journal, and participants at the Society for the Philosophy of Sex and Love session at the Pacific APA, 2016. 